\title{
Efficiency of slaughterhouse surveillance for the detection of bovine tuberculosis in cattle in Northern Ireland
}

\author{
A. V. PASCUAL-LINAZA ${ }^{1 *}$, A. W. GORDON ${ }^{2}$, L. A. STRINGER ${ }^{3}$ AND \\ F. D. MENZIES ${ }^{4}$ \\ ${ }^{1}$ Surveillance and Antimicrobial Resistance, Department of Agriculture, Environment and Rural Affairs, \\ Dundonald House, Belfast, UK \\ ${ }^{2}$ Biometrics Branch, Agri-Food and Biosciences Institute, Belfast, UK \\ ${ }^{3}$ Animal and Plant Health Agency, New Haw, Addlestone, Surrey, UK \\ ${ }^{4}$ Veterinary Epidemiology Unit, Department of Agriculture, Environment and Rural Affairs, Dundonald House, \\ Belfast, $U K$
}

Received 19 April 2016; Final revision 31 October 2016; Accepted 28 November 2016; first published online 28 December 2016

\section{SUMMARY}

Post-mortem examination continues to play an important surveillance role in the bovine tuberculosis (bTB) eradication programme in Northern Ireland. It is estimated that $18-28 \%$ of new bTB herd breakdowns are disclosed by the detection of bTB lesions in animals routinely slaughtered. The purpose of this study was to compare the performance of different slaughterhouses in Northern Ireland in detecting bTB-lesioned animals at routine slaughter (LRS) and to apply the findings to maximize the sensitivity of bTB slaughterhouse surveillance. Univariate statistical analysis on cattle slaughtered in Northern Ireland during 2011-2013 revealed that the risk of LRS disclosure varied between slaughterhouses, ranging from $0.08 \%$ to $0.54 \%$. Furthermore, the risk of confirmation of these LRS as bTB varied between slaughterhouses, ranging from $57 \cdot 9 \%$ to $72 \cdot 4 \%$. Logistic regression modelling of selected risk factors found that the risk of LRS disclosure increased with age, and was higher in purchased animals, during winter months, in animals coming from high bTB incidence areas and in animals slaughtered from herds with a bTB restriction in the last 2-3 years. Adjusting for these selected factors, the risk of LRS disclosure and bTB confirmation changed very little from the univariable analysis, suggesting that differences in disclosure risks between slaughterhouses were likely to be due to factors related to the slaughterhouses, rather than to the risk status of the animals presented. Examination of procedures within these slaughterhouses is recommended to identify ways that could increase the sensitivity of their bTB surveillance.

Key words: Abattoir, bovine tuberculosis, post-mortem examination, slaughterhouse, surveillance.

\section{INTRODUCTION}

Bovine tuberculosis (bTB) is an economically important chronic infectious disease that typically affects

\footnotetext{
* Author for correspondence: Ms. A. V. Pascual-Linaza, Surveillance and Antimicrobial Resistance, Department of Agriculture, Environment and Rural Affairs, Dundonald House, Belfast BT43SB, UK.

(Email:ana.pascual@daera-ni.gov.uk)
}

cattle, but that may also infect many other species, including humans.

Abattoir monitoring for bTB is a key surveillance component in countries with endemic infection, as well as in officially tuberculosis (TB)-free countries where meat inspection is the cornerstone for granting and maintaining official TB-free (OTF) status [1-5]. 
In Northern Ireland (NI), bTB is endemic in cattle, with significant economic and social consequences for the country and the farming community. Compulsory eradication of bTB began in 1959 and after initial rapid progress (reaching levels of $<1 \%$ herd incidence during the 1960s), increasing herd incidence was observed during the late 1980s reaching a peak annual herd incidence in February 2003 (10.2\%). A declining herd incidence followed but this levelled off (20072010; 5-6\% bTB herd incidence) with a 2010 annual bTB herd incidence of $5 \cdot 12 \%$; its lowest level since 1998. A sharp rise took place in 2011 and this continued in 2012 when annual herd incidence was 7.34\%. However, over 2013 herd incidence fell to $6 \cdot 44 \%$. The annual animal incidence has followed similar trends and it was $0.51 \%$ in 2013. In 2013, the confirmed bTB herd prevalence was $7 \cdot 17 \%$ [6] and the cost of the eradication programme undertaken by the Department of Agriculture, Environment and Rural Affairs (DAERA) (formerly Department of Agriculture and Rural Development; DARD) was $£ 27$ million [7]. The programme consists of two surveillance components: live-animal surveillance and slaughterhouse surveillance [8]. The former is based on the single comparative intradermal tuberculin test (SCITT) and supplemented under specific circumstances with a gamma-interferon test. The sensitivity of the SCITT test has been estimated to be $56 \%$ [95\% confidence interval (CI) 52.9-60.8] in the Republic of Ireland (ROI) [9], whereas previous studies in other countries suggest that SICCT test sensitivity lies between $52 \%$ and $100 \%$, with median values of $80 \%$ and $93 \cdot 5 \%$ for standard and severe interpretations, respectively [10]. Animals that react positively to the SCITT and high-risk in-contact animals are slaughtered, their herd of origin is placed under movement restrictions, and one clear whole-herd test 60 days after the removal of positive animals (among other measures) is needed for the herd to regain trading status (two clear tests 60 days apart if bTB infection is confirmed).

Animals with negative results to the live-animal surveillance tests are subjected to post-mortem examination (PME) when routinely slaughtered in accordance with EC directive 854/2004 [11]. All carcasses are examined for, among other things, visible signs of bTB infection.

When visible lesions suspicious of bTB infection are detected in animals that are not compulsorily slaughtered under the bTB programme, the animal is described as having a 'lesion at routine slaughter' (LRS) and a disease control response is automatically initiated by DAERA. The herd from which the slaughtered animal originated is subject to movement restrictions until confirmation or otherwise of Mycobacterium bovis as the cause of the lesion. Confirmation is established by follow-up testing by histological and bacteriological examination of the bTB-like lesions [12] at the Agri-Food and Biosciences Institute (AFBI) laboratory.

Costello et al. found that $10 \%$ of animals in bTB-infected herds that had visible bTB lesions did not react to the SCITT [13]. Moreover, an unpublished report from the Veterinary Epidemiology Unit (DAERA) (A. V. Pascual-Linaza, unpublished report) estimated that in NI between $5 \cdot 2 \%$ and $6 \cdot 4 \%$ of all disclosed bTB-infected animals were detected at PME during the years 2011-2013. Despite annual herd testing in NI, $18 \%-28 \%$ of the newly confirmed bTB breakdowns were first detected through slaughterhouse surveillance. The number and distribution of LRS animals is thus a useful ancillary measure of the underlying disease levels and trends within the national herd because it represents a sampling system that is independent of live-animal surveillance.

Thus, PME forms an effective surveillance method for detecting residual bTB infection as well as for monitoring infection trends in the population, and there is a need to regularly assess its efficacy and efficiency. However, the sensitivity of the PME is likely to be low and dependent upon different host, agent, and environmental factors [14].

The aim of this study was to assess the variation in LRS detection risks between different NI slaughterhouses. The results from the study provide evidence for bTB policy makers on the current performance of slaughterhouse surveillance for bTB in NI, so they can target possible enhancements of the current bTB eradication programme.

\section{MATERIALS AND METHODS}

NI has 10 bovine slaughterhouses spread throughout the country (Fig. 1). Detailed information on all animals slaughtered in NI from 2011 to 2013 inclusive was extracted from the Animal and Public Health Information System (APHIS), which is a database used in NI since 1988 to record the details of all individual cattle, cattle holdings, cattle movements and tests [15].

\section{Case definitions}

Disclosure of an LRS was defined as the submission of lymph node/tissue sample(s) from an animal with 


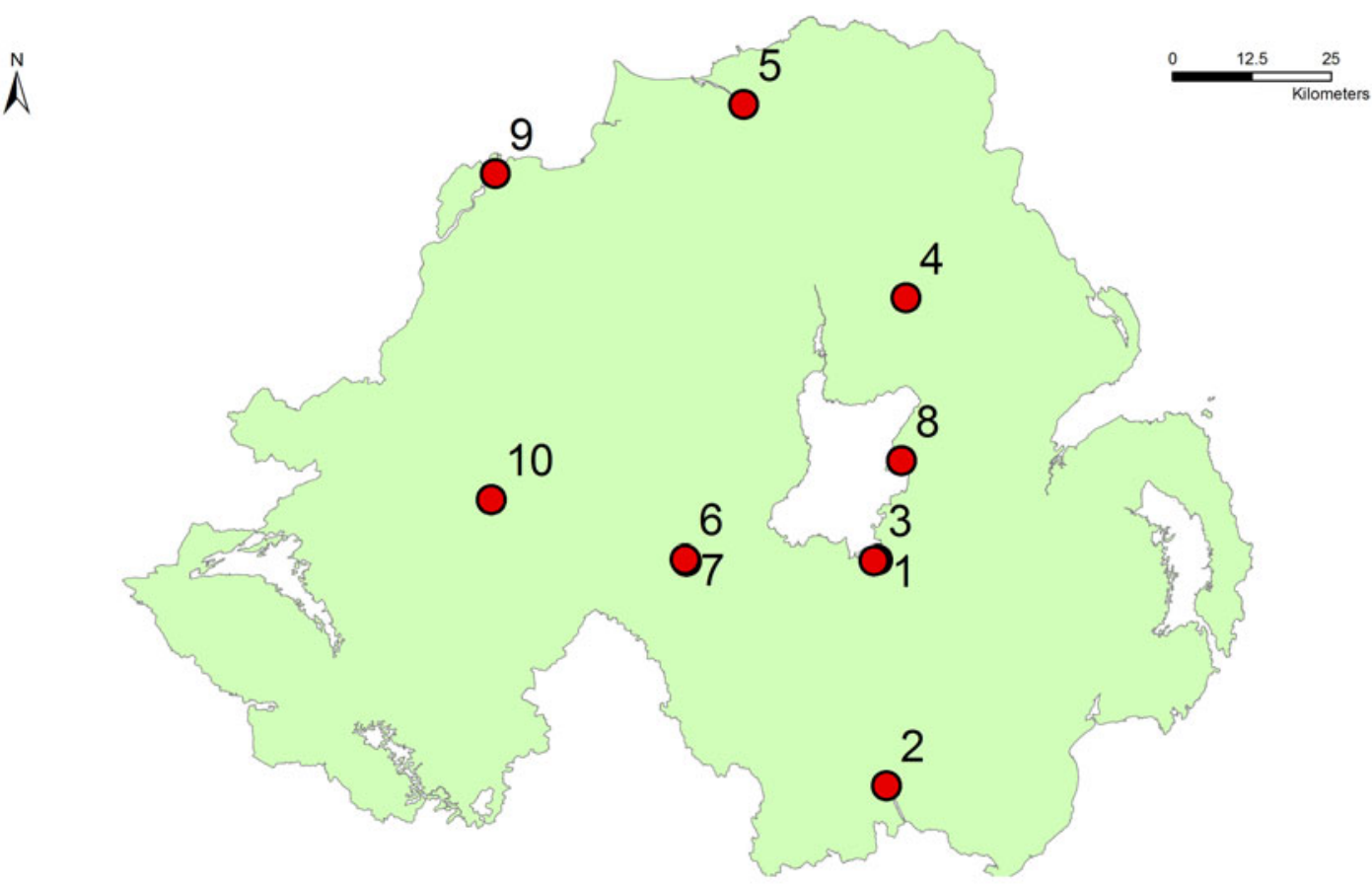

Agriculture, Environment and Rural Affairs
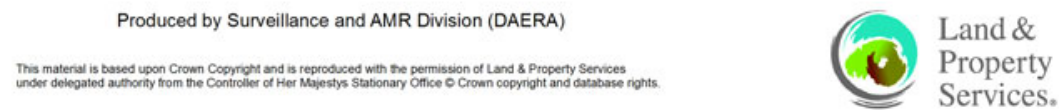

Fig. 1. Location of the ten bovine slaughterhouses in Northern Ireland.

suspected visible lesions of bTB infection identified at routine slaughter to the AFBI laboratory. Routine PMEs include visual examination of the carcass; palpation of the lungs, liver and tongue; incision of the lungs, heart and liver; as well as incision of head (submaxillar, parotid and retropharyngeal) and chest (apical, bronchial, mediastinal) lymph nodes. When bTB lesions are identified in one tissue, a more detailed examination of the rest of the carcass is carried out.

LRS confirmation was defined as the presence of histopathological features consistent with bTB and/ or bacteriological culture of Mycobacterium bovis following examination at AFBI on suspect lesions. All disclosed LRS undergo a histopathological examination and a bacteriological culture. Of the 2210 confirmed LRS in this study, M. bovis was recovered from $78 \%$ (1741).

\section{Data collation and analysis}

Data on cattle slaughtered in NI between 2011 and 2013 inclusive were collated, including those on animal- and herd-level factors, movements and TB history of the herd of origin of the animals.
Selected potential risk factors included in the statistical analysis were: sex and age of the animal; whether the animal was purchased or homebred; the season when the animal was slaughtered; the years that the herd of origen was free of bTB, the patch bTB incidence for each year under study and the slaughterhouse. These factors were categorized as indicated in Table 1.

Data on the herd of origin of the animal were taken either from the presenting herd (H0), if the animal had spent $\geqslant 75$ days in this herd, or from the previous herd from which the animal was purchased (H1), if it had spent $<75$ days in H0. This decision was taken based on peer-reviewed articles in which a minimum period of 2-3 months was reported as the time needed for an infected animal to develop visible lesions [16, 17].

During the descriptive analysis, it was observed that there was a possible linear effect of age on the disclosure of LRS. A better fit of the model was achieved including this variable as continuous in the multilevel statistical analysis.

There are 10 Divisional Veterinary Offices (DVOs) that are managed separately although following the same staff instructions. These DVOs are divided in a total of 124 patches, 6-16 patches per DVO. A 
Table 1. Distribution of numbers and percentages of slaughtered animals from 2011 to 2013 within each of the categories of variables considered. Distribution of numbers and percentages of LRS disclosed and confirmed from 2011 to 2013 within each of the categories of variables considered

\begin{tabular}{|c|c|c|c|c|c|c|}
\hline Variables & Category & $\begin{array}{l}\text { No. } \\
\text { slaughtered } \\
(\%)\end{array}$ & $\begin{array}{l}\text { No. of LRS } \\
\text { disclosures }\end{array}$ & $\begin{array}{l}\text { Percentage of } \\
\text { slaughtered } \\
\text { animals disclosed } \\
\text { as LRS (risk \%) }\end{array}$ & $\begin{array}{l}\text { No. of LRS } \\
\text { confirmation }\end{array}$ & $\begin{array}{l}\text { Percentage of } \\
\text { confirmed } \\
\text { LRSs (risk \%) }\end{array}$ \\
\hline \multirow[t]{3}{*}{ Sex } & Male & $589150(48 \cdot 0)$ & 1476 & $0 \cdot 3$ & 903 & $61 \cdot 1$ \\
\hline & Female & $603414(49 \cdot 2)$ & 1982 & $0 \cdot 3$ & 1246 & $62 \cdot 9$ \\
\hline & Bull & $34730(2 \cdot 8)$ & 100 & $0 \cdot 3$ & 61 & 61 \\
\hline \multirow[t]{9}{*}{ Age (years) } & $<1$ & $875(0 \cdot 1)$ & 15 & $1 \cdot 7$ & 1 & $6 \cdot 7$ \\
\hline & 1 to $<2$ & $146973(12 \cdot 0)$ & 283 & $0 \cdot 2$ & 166 & $58 \cdot 7$ \\
\hline & 2 to $<3$ & $680015(55 \cdot 4)$ & 1804 & $0 \cdot 3$ & 1094 & $60 \cdot 6$ \\
\hline & 3 to $<4$ & $138001(11 \cdot 2)$ & 434 & $0 \cdot 3$ & 266 & $61 \cdot 3$ \\
\hline & 4 to $<5$ & $42323(3 \cdot 4)$ & 131 & $0 \cdot 3$ & 76 & 58 \\
\hline & 5 to $<6$ & $35116(2 \cdot 9)$ & 124 & $0 \cdot 4$ & 87 & $70 \cdot 2$ \\
\hline & 6 to $<7$ & $32183(2 \cdot 6)$ & 112 & $0 \cdot 3$ & 77 & $68 \cdot 8$ \\
\hline & 7 to $<8$ & $30481(2 \cdot 5)$ & 147 & $0 \cdot 5$ & 95 & $64 \cdot 6$ \\
\hline & $\geqslant 8$ & $121327(9 \cdot 9)$ & 508 & $0 \cdot 4$ & 348 & $68 \cdot 5$ \\
\hline \multirow[t]{4}{*}{ Season } & Jan.-Mar. & $312073(25 \cdot 4)$ & 948 & $0 \cdot 3$ & 588 & $62 \cdot 1$ \\
\hline & Apr.--June & $295111(24 \cdot 0)$ & 806 & $0 \cdot 3$ & 473 & $58 \cdot 7$ \\
\hline & July-Sept. & $287391(23 \cdot 4)$ & 790 & $0 \cdot 3$ & 531 & $67 \cdot 3$ \\
\hline & Oct.-Dec. & $332719(27 \cdot 1)$ & 1014 & $0 \cdot 3$ & 618 & $60 \cdot 7$ \\
\hline \multirow{2}{*}{ Purchased } & Homebred & $317966(25 \cdot 9)$ & 867 & $0 \cdot 3$ & 560 & $64 \cdot 6$ \\
\hline & Purchased & $909328(74 \cdot 1)$ & 2691 & $0 \cdot 3$ & 1654 & $61 \cdot 3$ \\
\hline \multirow{5}{*}{$\begin{array}{l}\text { OTF time } \\
\text { (years) }\end{array}$} & Restricted & $938860(76 \cdot 5)$ & 2787 & $0 \cdot 3$ & 1758 & $63 \cdot 1$ \\
\hline & $<1$ & $203778(16 \cdot 6)$ & 545 & $0 \cdot 3$ & 320 & $58 \cdot 7$ \\
\hline & 1 to $<2$ & $80539(6 \cdot 6)$ & 203 & $0 \cdot 3$ & 116 & $57 \cdot 1$ \\
\hline & 2 to $<3$ & $1698(0 \cdot 1)$ & 12 & $0 \cdot 7$ & 9 & 75 \\
\hline & $>3$ & $2419(0 \cdot 2)$ & 11 & $0 \cdot 5$ & 7 & $63 \cdot 6$ \\
\hline \multirow{5}{*}{ Patch incidence } & $<\mathrm{Q} 1$ & $249579(20 \cdot 3)$ & 687 & $0 \cdot 3$ & 403 & $58 \cdot 7$ \\
\hline & $\begin{array}{l}\geqslant \mathrm{Q} 1 \text { to } \\
<\mathrm{Med}\end{array}$ & $314650(25 \cdot 6)$ & 814 & $0 \cdot 3$ & 494 & $60 \cdot 6$ \\
\hline & $\begin{array}{l}\geqslant \text { Med to } \\
<\text { Q3 }\end{array}$ & $321182(24 \cdot 1)$ & 857 & $0 \cdot 3$ & 530 & $61 \cdot 8$ \\
\hline & $\geqslant Q 3$ & $341883(27 \cdot 9)$ & 1200 & $0 \cdot 4$ & 784 & $65 \cdot 3$ \\
\hline & 1 & $138299(11 \cdot 3)$ & 324 & $0 \cdot 2$ & 218 & $67 \cdot 3$ \\
\hline \multirow{9}{*}{ Slaughter house } & 2 & $165941(13 \cdot 5)$ & 699 & $0 \cdot 4$ & 430 & $61 \cdot 5$ \\
\hline & 3 & $39057(3 \cdot 2)$ & 30 & $0 \cdot 1$ & 22 & 70 \\
\hline & 4 & $61872(5 \cdot 0)$ & 199 & $0 \cdot 3$ & 144 & $72 \cdot 4$ \\
\hline & 5 & $161297(13 \cdot 1)$ & 655 & $0 \cdot 4$ & 382 & $58 \cdot 5$ \\
\hline & 6 & $206281(16 \cdot 8)$ & 737 & $0 \cdot 4$ & 427 & $57 \cdot 9$ \\
\hline & 7 & $163976(13 \cdot 4)$ & 327 & $0 \cdot 2$ & 212 & $64 \cdot 5$ \\
\hline & 8 & $6065(0 \cdot 5)$ & 33 & $0 \cdot 5$ & 20 & $60 \cdot 6$ \\
\hline & 9 & $129591(10 \cdot 6)$ & 212 & $0 \cdot 2$ & 137 & $65 \cdot 1$ \\
\hline & 10 & $154915(12 \cdot 6)$ & 342 & $0 \cdot 2$ & 218 & $63 \cdot 7$ \\
\hline Total & & $1227294(100)$ & 3558 & $0 \cdot 3$ & 2210 & 62 \\
\hline
\end{tabular}

LRS, Lesion at routine slaughter; OTF, officially tuberculosis free; Q1, first quartile; Med, median; Q3, third quartile.

patch was defined as an administrative area within each of the DVO areas in NI (Fig. 2).

Animals with missing data (i.e. age, DVO/patch or herd information), which constituted $8.5 \%$ of the original dataset, were excluded from the study.
The majority of these missing data $(95 \%)$ was due to imported animals going directly to slaughter.

Microsoft Access ${ }^{\mathrm{TM}}$ and MS Excel ${ }^{\mathrm{TM}}$ (Microsoft Corporation, USA) were used for data manipulation.

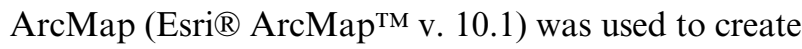


Table 2. Univariable and multivariable (logistic regression) model outputs of risk factors for the disclosure of bTB lesions in cattle at routine slaughter (LRS)

\begin{tabular}{|c|c|c|c|c|c|}
\hline \multirow[b]{2}{*}{ Variable } & \multirow[b]{2}{*}{ Category } & \multicolumn{2}{|c|}{ Univariable } & \multicolumn{2}{|c|}{ Multivariable } \\
\hline & & $P$ value & OR $(95 \% \mathrm{CI})$ & $P$ value & OR $(95 \% \mathrm{CI})$ \\
\hline Age (years) & Per year older & $<0 \cdot 001$ & $1 \cdot 07(1 \cdot 06-1 \cdot 08)$ & $<0.001$ & $1.06(1.04-1 \cdot 07)$ \\
\hline \multirow[t]{3}{*}{ Sex } & Male & - & 1 (ref.) & - & 1 (ref.) \\
\hline & Female & $<0 \cdot 001$ & $1 \cdot 31(1 \cdot 23-1 \cdot 4)$ & $<0 \cdot 001$ & $1 \cdot 20(1 \cdot 11-1 \cdot 30)$ \\
\hline & Bull & $0 \cdot 175$ & $1 \cdot 15(0 \cdot 94-1 \cdot 41)$ & $0 \cdot 323$ & $1 \cdot 11(0 \cdot 9-1 \cdot 36)$ \\
\hline \multirow[t]{4}{*}{ Slaughter season } & Jan.-Mar. & - & 1 (ref.) & - & 1 (ref.) \\
\hline & Apr.-June & $0 \cdot 025$ & $0.90(0.82-0.99)$ & $0 \cdot 042$ & $0 \cdot 91(0 \cdot 83-1)$ \\
\hline & July-Sept. & 0.036 & $0.90(0.82-0.99)$ & $0 \cdot 007$ & $0.89(0.80-0.96)$ \\
\hline & Oct.-Dec. & $0 \cdot 942$ & $1(0 \cdot 92-1 \cdot 1)$ & $0 \cdot 604$ & $0.98(0.89-1.07)$ \\
\hline \multirow[t]{4}{*}{ Patch incidence } & $<\mathrm{Q} 1$ & - & 1 (ref.) & - & 1 (ref.) \\
\hline & $\geqslant \mathrm{Q} 1$ to $<\mathrm{Med}$ & $0 \cdot 226$ & $0.94(0 \cdot 85-1 \cdot 04)$ & $0 \cdot 589$ & $0.97(0 \cdot 88-1 \cdot 08)$ \\
\hline & $\geqslant$ Med to $<\mathrm{Q} 3$ & $0 \cdot 539$ & $0.97(0 \cdot 88-1.07)$ & $0 \cdot 486$ & $0.96(0.87-1.07)$ \\
\hline & $\geqslant Q 3$ & $<0 \cdot 001$ & $1 \cdot 28(1 \cdot 16-1 \cdot 4)$ & $<0 \cdot 001$ & $1 \cdot 19(1 \cdot 08-1 \cdot 31)$ \\
\hline \multirow[t]{5}{*}{ OTF time (years) } & bTB-restricted & - & 1 (ref.) & - & 1 (ref.) \\
\hline & $<1$ & $0 \cdot 025$ & $0.90(0.82-0.99)$ & $0 \cdot 020$ & $0.90(0.82-0.98)$ \\
\hline & 1 to $<2$ & 0.023 & $0.85(0.74-0.98)$ & $0 \cdot 027$ & $0.85(0.74-0.98)$ \\
\hline & 2 to $<3$ & $0 \cdot 003$ & $2 \cdot 39(1 \cdot 35-4 \cdot 22)$ & $0 \cdot 016$ & $2 \cdot 01(1 \cdot 14-3 \cdot 56)$ \\
\hline & $\geqslant 3$ & $0 \cdot 157$ & $1 \cdot 53(0 \cdot 85-2 \cdot 78)$ & $0 \cdot 167$ & $1.53(0.84-2 \cdot 76)$ \\
\hline \multirow[t]{2}{*}{ Purchased } & Homebred & - & 1 (ref.) & - & 1 (ref.) \\
\hline & Purchased & $0 \cdot 034$ & $1.09(1 \cdot 01-1 \cdot 17)$ & $<0.001$ & $1 \cdot 22(1 \cdot 12-1 \cdot 32)$ \\
\hline$\sigma^{2}$ (s.E.) & & & & Slh: $0 \cdot 30$ & \\
\hline
\end{tabular}

OR, Odds ratio; CI, confidence interval; OTF, officially tuberculosis free; Q1, first quartile; Med, median; Q3, third quartile; $\sigma^{2}$, variance; s.E., standard error of the random effect slaughterhouse (Slh).

Table 3. Univariable and multivariable (logistic regression) outputs of risk factors for the confirmation of bTB lesions in cattle at routine slaughter (LRS)

\begin{tabular}{|c|c|c|c|c|c|}
\hline \multirow[b]{2}{*}{ Variable } & \multirow[b]{2}{*}{ Category } & \multicolumn{2}{|c|}{ Univariable } & \multicolumn{2}{|c|}{ Multivariable } \\
\hline & & $P$ value & OR $(95 \% \mathrm{CI})$ & $P$ value & OR $(95 \% \mathrm{CI})$ \\
\hline Age (years) & Per year older & $<0 \cdot 001$ & $1 \cdot 05(1 \cdot 02-1 \cdot 07)$ & $<0.001$ & $1 \cdot 05(1 \cdot 03-1 \cdot 08)$ \\
\hline \multirow[t]{3}{*}{ Sex } & Male & - & 1 (ref.) & - & 1 (ref.) \\
\hline & Female & $0 \cdot 28$ & $1.08(0 \cdot 94-1 \cdot 24)$ & 0.553 & $0.95(0 \cdot 81-1 \cdot 12)$ \\
\hline & Bull & $0 \cdot 98$ & $1(0 \cdot 66-1 \cdot 51)$ & 0.559 & $0.89(0.58-1 \cdot 36)$ \\
\hline \multirow[t]{4}{*}{ Slaughter season } & Jan.-Mar. & - & 1 (ref.) & - & 1 (ref.) \\
\hline & Apr.-June & $0 \cdot 14$ & $0 \cdot 87(0 \cdot 71-1 \cdot 05)$ & $0 \cdot 257$ & $0.88(0.73-1.07)$ \\
\hline & July-Sept. & 0.023 & $1 \cdot 26(1 \cdot 03-1 \cdot 53)$ & $0 \cdot 024$ & $1 \cdot 25(1.03-1 \cdot 53)$ \\
\hline & Oct.-Dec. & $0 \cdot 529$ & $0.94(0 \cdot 79-1 \cdot 13)$ & $0 \cdot 627$ & $0.95(0 \cdot 79-1 \cdot 14)$ \\
\hline \multirow[t]{4}{*}{ Patch incidence } & $<\mathrm{Q} 1$ & - & 1 (ref.) & - & 1 (ref.) \\
\hline & $\geqslant \mathrm{Q} 1$ to $<\mathrm{Med}$ & $1 \cdot 082$ & $1 \cdot 08(0 \cdot 88-1 \cdot 33)$ & $0 \cdot 327$ & $1 \cdot 10(0 \cdot 89-1 \cdot 36)$ \\
\hline & $\geqslant$ Med to $<\mathrm{Q} 3$ & $0 \cdot 203$ & $1 \cdot 14(0 \cdot 93-1 \cdot 4)$ & $0 \cdot 112$ & $1 \cdot 17(0.95-1 \cdot 44)$ \\
\hline & $\geqslant Q 3$ & $0 \cdot 004$ & $1 \cdot 33(1 \cdot 1-1 \cdot 61)$ & $0 \cdot 002$ & $1 \cdot 35(1 \cdot 11-1 \cdot 64)$ \\
\hline \multirow[t]{5}{*}{ OTF time (years) } & bTB-restricted & - & 1 (ref.) & - & 1 (ref.) \\
\hline & $<1$ & $0 \cdot 054$ & $0.83(0 \cdot 69-1)$ & $0 \cdot 005$ & $0.77(0.63-0.93)$ \\
\hline & 1 to $<2$ & 0.092 & $0 \cdot 78(0 \cdot 59-1 \cdot 04)$ & 0.053 & $0.76(0.56-1 \cdot 01)$ \\
\hline & 2 to $<3$ & $0 \cdot 398$ & $1 \cdot 76(0 \cdot 48-6 \cdot 49)$ & $0 \cdot 335$ & $1.86(0.49-6.99)$ \\
\hline & $\geqslant 3$ & $0 \cdot 969$ & $1 \cdot 02(0 \cdot 3-3 \cdot 49)$ & $0 \cdot 981$ & $1 \cdot 01(0 \cdot 29-3 \cdot 50)$ \\
\hline \multirow[t]{2}{*}{ Purchased } & Homebred & - & 1 (ref.) & - & 1 (ref.) \\
\hline & Purchased & $0 \cdot 08$ & $0 \cdot 87(0 \cdot 74-1 \cdot 02)$ & $0 \cdot 017$ & $0 \cdot 83(0 \cdot 70-0 \cdot 98)$ \\
\hline \multicolumn{4}{|l|}{$\sigma^{2}$ (s.E.) } & \multicolumn{2}{|c|}{ Slh: $0.039(0.027)$} \\
\hline
\end{tabular}

OR, Odds ratio; CI, confidence interval; OTF, officially tuberculosis free; Q1, first quartile; Med, Median; Q3, third quartile; $\sigma^{2}$, variance; s.E., standard error of the random effect slaughterhouse (Slh). 


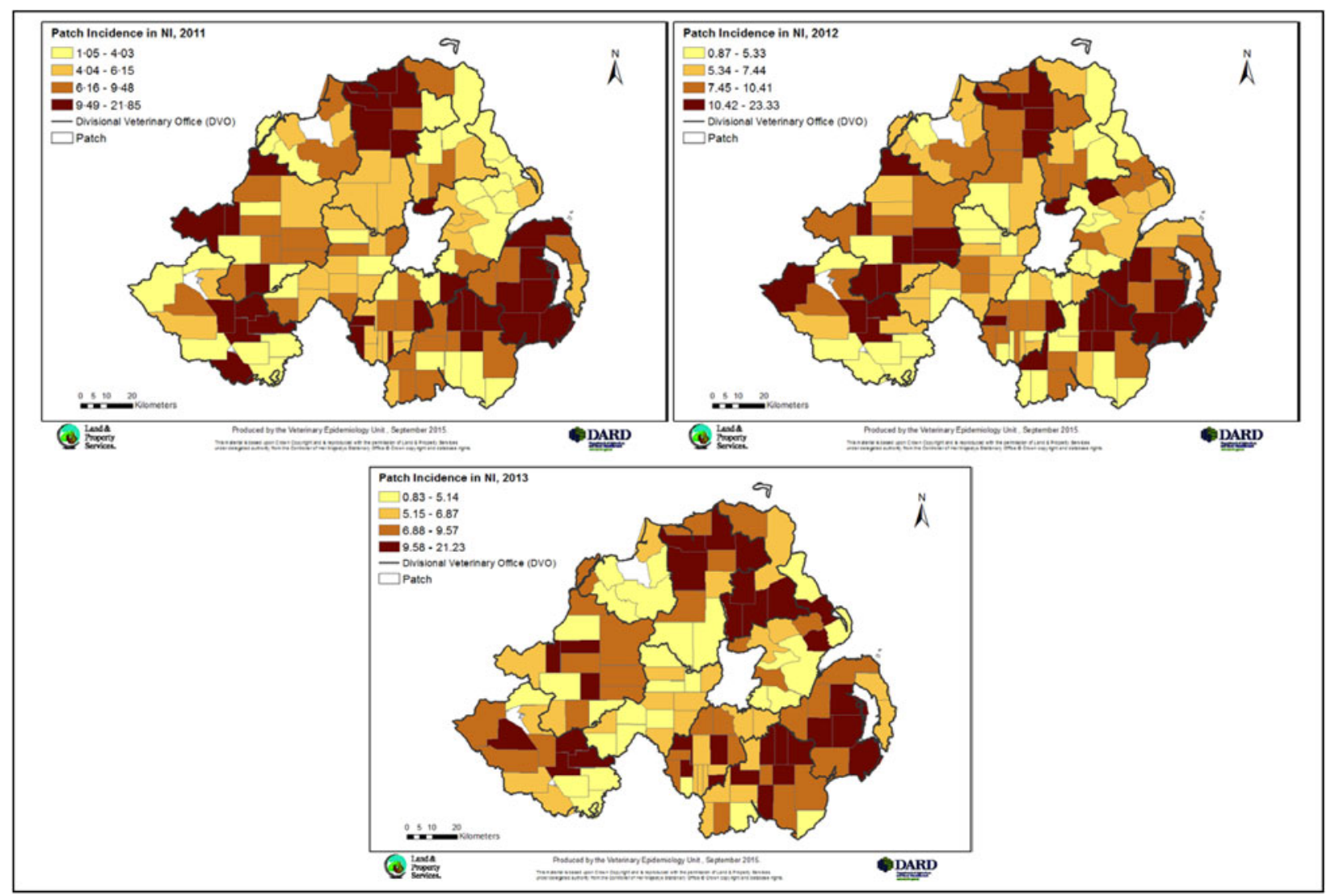

Fig. 2. Geographical representation of patch incidences (minimum, first quartile, median, third quartile and maximum values used to create the four categories represented) in 2011, 2012 and 2013 in Northern Ireland.

the geographical representation of patch incidences and the location of the slaughterhouses.

For the estimation of the selected risk factors associated with LRS disclosure and confirmation (Table 1), a univariable, followed by a multivariable, generalized linear mixed model using a binomial distribution and a logit link function was generated in GenStat (GenStat for Windows 16th edn, VSN International Ltd, UK) and slaughterhouse was fitted as a random effect in order to account for within slaughterhouse variance. Collinearity between the various explanatory variables was assessed using the variance inflation factor [18]. All values were $<10$ thus collinearity was not considered an issue. The method used to assess the linearity of the explanatory variables was the method of design variables [19]. It was decided that in the interests of parsimony that any variable that was not linear was categorized using biologically appropriate cut-offs.

All explanatory variables were fitted in the first instance with the intention to use backward elimination; each explanatory variable in turn was then assessed by comparing the significance of its Wald statistic against all other terms using an appropriate $\chi^{2}$ distribution. Any terms with $P<0.05$ were included in the final model. Because all selected variables were significant (for submission model) backward elimination was not necessary. Some of the variables were not significant for the confirmation model, but were maintained for consistency between the two multivariable models.

A generalized linear model was ran in GenStat to rank the slaughterhouses on LRS disclosure and LRS confirmation. We first calculated the crude risk for each of the slaughterhouses reporting animals with LRS and then, using the results of the logistic regression model, we calculated the risk for each slaughterhouse disclosing an LRS, adjusted for confounders. The Pearson correlation coefficient between LRS submissions and bTB confirmation was derived. Interactions between variables were also investigated in both models. Statistical significance was set at the $5 \%$ level. The adequacy of the models was assessed 
by the Hosmer-Lemeshow test and by visual inspection of the appropiate residual plots.

\section{RESULTS}

\section{Descriptive results}

There were 1341886 cattle slaughtered in the 10 approved bovine slaughter establishments in NI between 2011 and 2013 (ranging from 6065 to 206281 by slaughterhouse). After exclusion of animals with missing data, analysis was carried out on 1227294 cattle from 22878 herds, of which 3558 $(0 \cdot 29 \%)$ animals had bTB-like lesions and 2210 $(0 \cdot 18 \%)$ were confirmed as bTB positive (Table 1$)$.

More than half $(55.4 \%)$ of the total animals slaughtered in NI between 2011 and 2013 were aged between 2 and 3 years. However, the highest risk of disclosure was found in animals aged $1-2$ years $(1 \cdot 7 \%)$, although the risk of a disclosed lesion being confirmed as bTB was the lowest $(6 \cdot 7 \%)$. Animals slaughtered at age $>5$ years accounted for $17.9 \%$ of the total slaughtered animals, and lesions detected in these animals had the highest risk of confirmation $(64 \cdot 6-70 \cdot 2 \%)$. Although the risk of disclosure was similar for all four slaughterhouse seasons $(0 \cdot 3 \%)$, a higher risk of confirmation was found in animals in which LRS were disclosed between July and September $(67 \cdot 3 \%$, cf. $58 \cdot 7 \%$ between April and June). Animals that originated in bTB-restricted herds accounted for $76.5 \%$ of the total animals slaughtered. However, a higher risk of LRS disclosure was found in animals that were presented for slaughter from herds that had a bTB breakdown in the previous $2-3$ years prior to their slaughter date ( $0 \cdot 7 \%$, cf. $0 \cdot 3 \%$ in animals from restricted herds). These animals also had the highest risk of confirmation ( $75 \%$, cf. $57 \cdot 1 \%$ in lesions from animals originating in herds with a bTB breakdown in the previous 1-2 years). Patch incidence maps for each of the 3 years under study (Fig. 2) were developed to evaluate the spatial distribution of bTB incidence, which ranged from $23.33 \%$ in 2012 to $0.83 \%$ in 2013. Animals from herds located in high-incidence patches (above the third quartile of each of the years: 9.48, 10.41 and $9 \cdot 57 \%$ from 2011 to 2013 , respectively; Fig. 2) accounted for $33 \cdot 7 \%(n=1200)$ of the LRS total, had a higher risk of disclosure than animals originated in lower incidence patches $(0 \cdot 4 \%$ vs. $0 \cdot 3 \%$ in other patches), and lesions detected had a higher risk of confirmation $(65 \cdot 3 \%$ vs. $58 \cdot 7 \%$ in animals from patches with incidence lower than first quartile).

\section{Statistical analysis: univariable and multivariable analysis}

\section{LRS disclosure}

For each year increase in age at slaughter the odds of that animal to be disclosed as an LRS increased by $1 \cdot 06$ (95\% CI 1.04-1.07) (Table 2).

In the univariable analysis, females had 1.31 times the odds of LRS disclosure than males (95\% CI $1 \cdot 23-1 \cdot 4)$. These odds remained higher in females than in males in the multivariable analysis, although the value was slightly lower [odds ratio (OR) $1 \cdot 20,95 \%$ CI 1·11-1·30]. There was no difference on the odds of being a LRS disclosure between bulls and males in either the univariable or multivariable analysis.

Animals slaughtered from April to September were statistically less likely to be disclosed as LRS (OR 0.9, 95\% CI 0.82-0.99) in univariable analysis, although only animals slaughtered during the summer (JulySeptember) had lower odds of having an LRS disclosed (OR $0 \cdot 89,95 \%$ CI $0 \cdot 80-0 \cdot 96$ ) than those slaughtered during winter (January-March) in multivariable analysis.

Animals coming from patches where bTB incidence was above the third quartile $(9 \cdot 48,10 \cdot 41$ and $9 \cdot 47 \%$ in 2011, 2012 and 2013, respectively; Fig. 2) were more likely to be LRS disclosed (univariable analysis: OR $1 \cdot 28$, 95\% CI 1.16-1.4; multivariable analysis: OR $1 \cdot 19,95 \%$ CI $1 \cdot 08-1 \cdot 31$ ) than animals coming from patches where bTB incidence was below the first quartile in each year $(4 \cdot 03,5 \cdot 32$ and $5 \cdot 14 \%$ in 2011,2012 and 2013, respectively; Fig. 2).

Regarding the bTB status of the attributed herd of origin of the LRS (either $\mathrm{H} 0$ or H1), it was found that, relative to bTB-restricted herds, there was a higher chance of disclosing LRS in cattle originating from herds that had been clear of bTB for $2-3$ years (OR $2 \cdot 01,95 \%$ CI $1 \cdot 14-3 \cdot 56)$. There was no statistical difference between $\mathrm{bTB}$-restricted herds and herds that were clear of bTB for $>3$ years, either in the univariable or multivariable analysis.

Suspect LRS were more likely to be identified in purchased animals than from homebred animals in multivariable analysis (OR 1·22,95\% CI 1·12-1·32).

\section{LRS confirmation}

For every year increase in age of the animal in which an LRS was disclosed, there were higher odds of confirmation of bTB infection (OR 1.05 95\% CI 1.03-1.08) (Table 3). 
Table 4. LRS disclosure risk (expressed as a percentage) and ranking by slaughterhouse $(1=$ lowest risk and $10=$ high risk). Adjusted values by age, sex, slaughter season, patch incidence, OTF time and purchased variables

\begin{tabular}{lllllll}
\hline \hline & & \multicolumn{2}{l}{ Crude } & & \multicolumn{2}{l}{ Adjusted } \\
\cline { 3 - 4 } \cline { 6 - 7 } Slaughterhouse & $\begin{array}{l}\text { Number } \\
\text { slaughtered }\end{array}$ & Risk \% & Rank & & Risk \% & Rank \\
\hline 1 & 138299 & $0 \cdot 23$ & 5 & & $0 \cdot 23$ & 5 \\
2 & 165941 & $0 \cdot 42$ & 9 & & $0 \cdot 42$ & 9 \\
3 & 39057 & $0 \cdot 08$ & 1 & & $0 \cdot 08$ & 1 \\
4 & 61872 & $0 \cdot 32$ & 6 & & $0 \cdot 31$ & 6 \\
5 & 161297 & $0 \cdot 41$ & 8 & $0 \cdot 38$ & 8 \\
6 & 206281 & $0 \cdot 36$ & 7 & $0 \cdot 36$ & 7 \\
7 & 163976 & $0 \cdot 20$ & 3 & $0 \cdot 19$ & 3 \\
8 & 6065 & $0 \cdot 54$ & 10 & $0 \cdot 60$ & 10 \\
9 & 129591 & $0 \cdot 16$ & 2 & $0 \cdot 16$ & 2 \\
10 & 154915 & $0 \cdot 22$ & 4 & $0 \cdot 22$ & 4 \\
Total & 1227294 & & & & \\
Average & & $0 \cdot 29$ & & $0 \cdot 3$ & \\
\hline \hline
\end{tabular}

LRS, Lesion at routine slaughter; OTF, officially tuberculosis free.

Table 5. Crude and adjusted confirmation risk (expressed as a percentage) by slaughterhouse $(1=$ lowest risk and $10=$ high risk $)$. Adjusted values by age, sex, slaughter season, patch incidence, OTF time and purchased variables

\begin{tabular}{|c|c|c|c|c|c|}
\hline \multirow[b]{2}{*}{ Slaughterhouse } & \multirow[b]{2}{*}{ No. of LRS } & \multicolumn{2}{|l|}{ Crude } & \multicolumn{2}{|c|}{ Adjusted } \\
\hline & & Risk \% & Rank & Risk \% & Rank \\
\hline 1 & 324 & $67 \cdot 3$ & 8 & $67 \cdot 0$ & 8 \\
\hline 2 & 699 & $61 \cdot 5$ & 4 & $62 \cdot 2$ & 3 \\
\hline 3 & 30 & 70 & 9 & $73 \cdot 2$ & 9 \\
\hline 4 & 199 & $72 \cdot 4$ & 10 & $73 \cdot 2$ & 10 \\
\hline 5 & 655 & $58 \cdot 5$ & 2 & $56 \cdot 1$ & 1 \\
\hline 6 & 737 & $57 \cdot 9$ & 1 & $58 \cdot 1$ & 2 \\
\hline 7 & 327 & $64 \cdot 5$ & 6 & $64 \cdot 8$ & 5 \\
\hline 8 & 33 & $60 \cdot 6$ & 3 & $64 \cdot 7$ & 4 \\
\hline 9 & 212 & $65 \cdot 1$ & 7 & $66 \cdot 3$ & 7 \\
\hline 10 & 342 & $63 \cdot 7$ & 5 & $64 \cdot 9$ & 6 \\
\hline Total & 3558 & & & & \\
\hline Average & & $64 \cdot 2$ & & $65 \cdot 1$ & \\
\hline
\end{tabular}

LRS, Lesion at routine slaughter; OTF, officially tuberculosis free.

Given that an LRS was detected, there was no statistical difference between males and females or between bulls and males in the odds of confirmation of the disease (OR $0 \cdot 95,95 \%$ CI $0 \cdot 81-1 \cdot 12$ for females and OR $0 \cdot 89,95 \%$ CI $0 \cdot 58-136$ for bulls).
LRSs found in summer (July-September) had a higher chance of being confirmed (univariable analysis: OR 1·26, 95\% CI 1·06-1.53; multivariable analysis: OR $1 \cdot 25,95 \%$ CI 1.03-1.53) than those found from January to March.

The LRSs disclosed in animals that originated in patches with a high incidence (above third quartile) had a higher chance of being confirmed as bTB (univariable analysis: OR $1 \cdot 33$; 95\% CI 1.1-1.61; multivariable analysis: OR $1 \cdot 35,95 \%$ CI $1 \cdot 11-1 \cdot 64$ ) than LRS disclosed in animals originated in low incidence patches (below the first quartile)

bTB status of the attributed herd of origin of the LRS was not statistical associated with confirmation of infection in either the univariable or the multivariable analysis.

LRSs disclosed in purchased animals were less likely to be confirmed as bTB by multivariable analysis (OR $0 \cdot 83$; 95\% CI $0 \cdot 70-0 \cdot 98$ ) than those in homebred animals.

\section{Ranking of slaughterhouses}

There was a wide range of crude LRS disclosure risks between some of the slaughterhouses (Table 4), from 0.08 to 0.54 ( $>6$ times the risk in slaughterhouse no. 8 than in slaughterhouse no. 3), with an average LRS disclosure risk of 0.3 across all slaughterhouses. The adjusted risk of LRS disclosure ranged from 0.08 (slaughterhouse no. 3) to 0.60 (slaughterhouse no. 8). The ranking of slaughterhouses by LRS disclosure risk did not change when adjusted for potential confounders.

The average crude risk for LRS confirmation was $64 \cdot 2 \%$ (Table 5) ranging from $57 \cdot 9 \%$ and $72 \cdot 4 \%$ and the average adjusted risk for LRS confirmation was $65 \cdot 1 \%$ (range $56 \cdot 1-73 \cdot 2 \%$ ). The ranking of the slaughterhouses regarding confirmation rates changed slightly when considering adjusted risk rather than crude. The crude LRS confirmation risk from slaughterhouse no. 8 was the most affected by adjusting for confounders (crude risk 60.6\%, adjusted risk 64.7\%).

Comparing the ranking for LRS disclosure (Table 4) to the ranking for LRS confirmation (Table 5), there appeared to be an inverse relationship (e.g. slaughterhouse nos. 8 and 3) although the risks were not significantly well correlated (crude risk: $r=-0.6004, P=$ 0.066; adjusted risk: $r=-0 \cdot 4709, P=0 \cdot 169$ ).

For the Hosmer-Lemeshow test, we obtained $P$ values $>0.05 \quad(P=0.538$ for the LRS disclosure model and $P=0.522$ for the LRS confirmation model), which indicated that the model was a good fit. 


\section{DISCUSSION}

This is the first study to assess the performance of different slaughterhouses in NI for the detection of bTB lesions in routinely slaughtered animals. It will enable DAERA policy makers to target improvements in slaughterhouse surveillance to enhance the bTB eradication programme.

PME in cattle is an important component of the bTB surveillance programme in NI; not only for the early detection of infected herds not yet disclosed by field surveillance (SCITT surveillance) or for detecting cattle that, for different reasons, were not disclosed as positives in the SCITT (e.g. anergic animals), but also to provide a supplementary means of monitoring the efficiency of field surveillance.

The LRS disclosure rate between 2011 and 2013 was 3 cattle/1000 slaughtered. Between $5 \cdot 2 \%$ and $6.4 \%$ of all confirmed bTB-infected animals in those three years were detected at PME (unpublished results). The proportion of new bTB breakdowns first detected through slaughterhouse surveillance ranged from $18 \%$ in 2012 to $28 \%$ in 2013 (unpublished results), which is similar to that reported previously for NI [20]. These figures give us an indication of the importance of slaughterhouse surveillance within the bTB eradication policy in NI. Similar figures were estimated in Great Britain (GB), where approximately $17 \%$ of all new OTF-status-withdrawn incidents detected in cattle herds every year (ranging from 16\% in endemic TB annual testing areas to $31 \%$ in four-yearly testing areas) were first disclosed by slaughterhouse surveillance [21]. In the ROI, 27$46 \%$ of new bTB breakdowns between 2003 and 2004 were initially detected at slaughter [22].

Our analysis standardized all slaughterhouses by considering differences in classes of cattle (age, whether they were purchased or not, and sex), time that the presenting herd had been free of bTB, incidence in the area of origin, and season of slaughter; this allowed a meaningful comparison of the risk of LRS disclosure and confirmation between different slaughterhouses.

There were substantial variations with regard to both LRS disclosure and bTB confirmation risks between the 10 approved bovine slaughter establishments in the country.

Ranking of the slaughterhouses by disclosure risk did not change between crude and adjusted analysis, which suggested that differences in the risk of disclosure and confirmation between slaughterhouses might be due to internal factors specific to slaughterhouses, such as line speed, light, and meat inspector performances [14, 22-24]. There is scope for improvement, specifically in those slaughterhouses where the risk of disclosure is low and that of confirmation is high. It would be of benefit to the bTB control programme to increase sensitivity at the cost of lowering the specificity of slaughterhouse surveillance for bTB. An investigation should be carried out in those slaughterhouses with lower LRS disclosure risk to identify and address those characteristics that might lower their ability to identify bTB.

This study did not consider production type which has been described in the literature as a risk factor for bTB. However, in our data, $82 \cdot 2 \%$ of the animals originated in beef production herds of which $76.7 \%$ were purchased. Beef cattle are very likely to be purchased instead of homebred and therefore we think that production type would have added similar information. Furthermore, purchase information was likely to have more biological meaning given that purchased animal would have more opportunities of becoming infected.

Factors such as age, slaughter season, patch incidence, time with OTF status, and whether the animal was purchased or homebred affected both the risk of LRS disclosure and LRS confirmation. The correlation between submission and confirmation was low and not statistically significant when adjusting for confounders. Animals killed between July and September were less likely to be identified as LRS, but their risk of being confirmed was higher compared with animals slaughtered between January and March. This may be related to diferences in transmission rates and testing frequency during grazing/housing seasons. Increased opportunities for infection transmission during the housing season [25], a decrease in SCITT surveillance during the grazing season and the time for lesions to develop after infection may lead to more likely LRS confirmation during July to September. The inverse relationship was also the case for purchased animals, which had more risk of having an LRS disclosed [26], but which were less likely to have the sample confirmed than homebred animals. Older animals had more chance of LRS disclosure, with the odds increasing with age. Studies on the associations between bTB and other cattle diseases, as well as between bTB and the location of bTB-like lesions, are currently being carried out by the Veterinary Sciences Division at the AFBI and by the Veterinary Epidemiology Unit in DAERA. Animals from herds located in high-incidence patches 
(above the third quantile; $9.48,10.41$ and 9.47 in 2011, 2012 and 2013, respectively; Fig 2) were more likely to have an LRS disclosed and confirmed as bTB in the laboratory.

Missing data for any of the variables used in the study accounted for $8.5 \%$ of the total slaughtered animals in NI, with $95 \%$ of these data being animals imported for direct slaughter. As part of an investigation of the proportionality of TB-positive animals imported from the ROI into NI from 2010 to 2012, it was reported that there was no statistical significance on the risk of LRS being detected and confirmed as bTB for cattle from NI compared with cattle imported from ROI for direct slaughter when adjusted for age, breed and sex (unpublished results). Therefore, we considered that these exclusions did not bias the study significantly.

It needs to be recognized that not all animals with bTB-like lesions would be found at PME, even if the examination technique were perfect and the conditions within the slaughterhouses were ideal for accurate examination. Some lesions are invisible to the naked eye. The primary complex is most frequently located in the lower parts of the respiratory tract and $70 \%$ of these lesions may only be found during careful examination and disection of the lungs into thin sections $[5,27]$. Also, it is important to highlight that not all infected animals have lesions at the time of slaughter. The existence of bTB lesions is directly related to the interplay between the host's defence mechanism and mycobacterial virulence factors [5]. A study in Australia comparing the sensitivity of routine slaughterhouse inspection procedures and detailed necropsy, estimated that slaughterhouse inspection failed to detect $47 \%$ of cattle with $\mathrm{TB}$ lesions [14]. This study concluded that the sensitivity of gross PME was affected by the method employed and the anatomical sites examined. Failure to detect visible lesions in TB skin reactors may be due to early infection and/or poor necropsy technique [28]. Indeed, McIlroy et al. found that $70 \%$ of lung lesions were $<1 \mathrm{~cm}$ in diameter in a study of TB reactors [23]. Experimental studies suggested that bTB lesions could be found in cattle as early as 14 days post-inoculation [29], whereas another study concluded that they could be found at 6-8 weeks post-infection [30]. Garcia-Saenz et al. estimated that the individual slaughterhouse surveillance sensitivity for bTB in Catalonia (Spain) was $31 \%(95 \%$ CI $28 \cdot 6-36 \cdot 2$ [31]. Therefore, the use of PME for the detection of bTB-infected animals is accepted as being poorly sensitive $[1,14,27]$.
These results are in broad agreement with the results from several studies in ROI and GB [22, 24, 32-34]. Especially in bTB endemic countries, an assessment of the efficiency of slaughterhouse surveillance to target improvements in inspection procedure is a useful tool to improve the country's eradication programme.

\section{CONCLUSIONS}

PME continues to play an important role in the bTB eradication programme in NI. The results of this study showed that there were differences in the risk of disclosure of bTB-like lesions in slaughtered cattle between slaughterhouses that could not be explained even when adjusted for selected variables related to animal and herd characteristics. Moreover, these differences might be explained by slaughterhouse-specific factors, such as inspection facilities or procedures. It is recommended that these slaughterhouses are assessed and areas that could be improved identified to increase detection of bTB, and therefore, improve the sensitivity of this surveillance component.

\section{ACKNOWLEDGEMENTS}

The authors thank Mark Woodside (DAERA) for extracting the data used in this study, and the Veterinary Officers (DAERA) and the Agri-Food and Biosciences Intitute for gathering part of the data used in this study.

This research received no specific grant from any funding agency, commercial or not-for-profit sectors.

\section{DECLARATION OF INTEREST}

None.

\section{REFERENCES}

1. Whipple DL, Bolin CA, Miller JM. Distribution of lesions in cattle infected with Mycobacterium bovis. Journal of Veterinary Diagnostic Investigation 1996; 8: 351-354.

2. Collins JD. Tuberculosis in cattle: strategic planning for the future. Veterinary Microbiology 2006; 112: 369-381.

3. Randuz B. Surveillance and risk management during the latter stages of eradication: Experiences from Australia. Veterinary Microbiology 2006; 112: 283-290.

4. Schiller I, et al. Bovine tuberculosis surveillance and diagnostics in Europe from the perspective of an officially tuberculosis free country: trade. Veterinary Microbiology 2011; 151: 153-159. 
5. Domingo M, Vidal E, Marco A. Pathology of bovine tuberculosis. Research in Veterinary Science 2014; 97 (Suppl.): S20-S29.

6. DAERA. Tuberculosis disease statistics, December 2013 (http://www.dardni.gov.uk/tb-stats-december2013.pdf). Accessed 12 August 2015.

7. DAERA, Bovine tuberculosis in Northern Ireland, 2013 Annual Report. November 2014 (https://www.daera-ni. gov.uk/sites/default/files/publications/dard/bovine-tuber culosis-tb-annual-report-2013.pdf). Accessed 16 July 2015.

8. Abernethy DA, et al. The Northern Ireland programme for the control and eradication of Mycobacterium bovis. Veterinary Microbiology 2006; 112: 231-237.

9. Clegg TA, et al. Using latent class analysis to estimate the test characteristics of the $\gamma$-interferon test, the single intradermal comparative tuberculin test and a multiplex immunoassay under Irish conditions. Veterinary Microbiology 2011; 151: 68-76.

10. De la Rua-Domenech R. et al. Ante mortem diagnosis of tuberculosis in cattle: A review of the tuberculin tests, $\gamma$-interferon assay and other ancillary diagnostic techniques. Research in Veterinary Science 2006; 81: 190-210.

11. EU - European Law. (http://eur-lex.europa.eu/ LexUriServ/LexUriServ.do?uri=OJ:L:2004:226:0083:0127: EN:PDF). Accessed 12 August 2015.

12. OIE Terrestrial Manual 2009. chapter 2.4.7 (http:// www.oie.int/fileadmin/Home/eng/Health_standards/tahm/ 2008/pdf/2.04.07_BOVINE_TB.pdf). Accessed 12 June 2016.

13. Costello E, et al. Performance of the single intradermal comparative tuberculin test in identifying cattle with tuberculous lesions in Irish herds. Veterinary Record 1997; 141: 222-224.

14. Corner LA, et al. Efficiency of inspection procedures for detection of tuberculosis lesion in cattle. Australian Veterinary Journal 1990; 67: 389-392.

15. Houston R. A computerised database system for bovine traceability. Scientific and Technical Review of the Office International des Epizooties (Paris) 2001; 20: 652-661.

16. Neill SD, et al. Pathogenesis of Mycobacterium bovis infection in cattle. Veterinary Microbiology 1994; 40: 41-52.

17. Martin SW, et al. Factors associated with the risk of, and the animal-level response to, Mycobacterium bovis in Irish cattle, 1993-1998. In: Selected Papers 20002001, Tuberculosis Investigation Unit, University College Dublin, 2001, pp. 1-8.

18. Cook RD, Weisberg S. In: Residuals and Influence in Regression. Chapman \& Hall, New York, 1982, p. 229.

19. Hosmer Jr. DW, Lemeshow S, Sturdivant RX. Applied Logistic Regression, 3rd edn. New Jersey: Wiley, 2013, pp. 94-107.

20. Krebs JR. Bovine tuberculosis in cattle and badgers. Report to the right Honourable Dr Jack Cunningham MP. p. 28. London: Ministry of Agriculture, Fisheries and Food, 1997 (http://www.bovinetb.info/docs/krebs. pdf). Accessed 2 July 2016.
21. Defra. Bovine TB Eradication Programme for England. July 2011. (http://www.defra.gov.uk/publications/files/ pb13601-bovinetb-eradication-programme-110719.pdf). Accessed 12 September 2014.

22. Frankena K, et al. Quantification of the relative efficiency of factory surveillance in the disclosure of tuberculosis lesions in attested Irish cattle. Veterinary Record 2007; 161: 679-684.

23. McIlroy SG, Neill SD, McCracken RM. Pulmonary lesions and Mycobacterium bovis excretion from respiratory tract of tuberculin reacting cattle. Veterinary Record 1986; 118: 718-721.

24. Olea-Popelka F, et al. Relative effectiveness of Irish factories in the surveillance of slaughtered cattle for visible lesions of tuberculosis, 2005-2007. Irish Veterinary Journal 2012; 65: 2.

25. Menzies FD, Neill SD. Cattle to cattle transmission of Bovine tuberculosis. Veterinary Journal, 2000; 160: 92-106.

26. Skuce RA, et al. Bovine tuberculosis (TB): a review of cattle to cattle transmission, risk factors and susceptibility. Bacteriology Branch Veterinary Sciences Division Agrifood and Biosciences Institute, October 2011. Section 2.5.2 (https://www.daera-ni.gov.uk/sites/ default/files/publications/dard/afbi-literature-review-tbreview-cattle-to-cattle-transmission.pdf). Accessed 4 June 2016.

27. De Kantor IN, et al. Tuberculous infection in cattle not detected by slaughterhouse inspection. Journal of Veterinary Medicine B 1987; 34: 202-205.

28. Corner LA. Post-mortem diagnosis of Mycobacterium bovis infection in cattle. Veterinary Microbiology 1994; 40: I53-63.

29. Cassidy JP, et al. Early lesion formation in cattle experimentally infected with Mycobacterium bovis. Journal of Comparative Pathology 1998; 119: 27-44.

30. Palmer MV, et al. Granualoma development in cattle after intratonsillar inoculation with Mycobacterium bovis. American Journal of Veterinary Research 1999; 60: $310-315$.

31. Garcia-Saenz A, et al. Estimation of the individual slaughterhouse surveillance sensitivity for bovine tuberculosis in Catalonia (North-Eastern Spain). Preventive Veterinary Medicine 2015; 121: 332-337.

32. Martin SW, O'Keeffe JJ, White P, Costello E. The relationship between the disclosure of tuberculous lesions in attested cattle and the factory, year, month and class of cattle in Ireland, 2001-2002. In: Selected Papers 20022003. Dublin, Veterinary Epidemiology and Tuberculosis Investigation Unit, University College Dublin. 2003, pp. 39-45.

33. Olea-Popelka F, et al. Risk factors for the disclosure of additional tuberculous cattle in attested-clear herds that had one animal with confirmed lesion of tuberculosis at slaughter during 2003 in Ireland. Preventive Veterinary Medicine 2008; 85: 81-91.

34. Shittu A, et al. Factors associated with bovine tuberculosis confirmation rates in suspect lesions found in cattle at routine slaughter in Great Britain, 2003-2008. Preventive Veterinary Medicine 2013; 110: 395-404. 